\title{
The Complexity of Relationships within Business and the Importance of Common Ground
}

\author{
Anna Ābeltiņa ${ }^{1, *}$, Ketevan Rizhamadze ${ }^{2}$ \\ ${ }^{1}$ EKA University of Applied Science, Rīga, LV-1019, Latvia \\ ${ }^{2}$ Turiba University, Riga, LV-1058, Latvia
}

\begin{abstract}
In today's rapidly evolving digital and social media dominated world, traditional marketing approaches are becoming obsolete. Companies are trying to alter the workplace into a vibrant one that enhances the talent of the people and to manage complex relationships inside and outside the organization. The following paper illustrates the complexity of relationships that companies have to handle. It is argued that the embeddedness of relationships plays a crucial role, notably in the business-to-business (B2B) relationship and that finding common ground is pivotal. The nature of the research methodology adopted for this study is primarily quantitative. All analyses are based on secondary data obtained through books, articles, and publications. The findings of the research indicate that the B2B relationship is a complex and multi-layered subject. Furthermore, for conflict resolution, taking into consideration the cultural differences in the decision-making process is fundamental. The presented study is exploratory in nature and therefore cannot be generalized for the general public. The findings are important for managers and entrepreneurs who need to be aware of the complexity of the business-to-business context. Although the nature of the study is exploratory, the study is original because it highlights some vital aspects upon which managers can reflect and dwell on.
\end{abstract}

Keywords: B2B marketing; relationships; complexity; decision-making process; organizational structure; SMEs

\section{Introduction}

In the face of the rapid pace of change, an organization should mobilize knowledge and technological skills, as well as be able to generate new products, processes and services. While companies tend to be the arrangement of complex systems, structures and strategies, managing business and non-business, formal and informal relationships with other players is an overwhelming task for managers. Within the past decade, it has been empirically shown that company managers are responsible for handling complex relationship models and are liable for the responsiveness and the capability of staff members to grasp and succeed in a competitive environment. Previous research in the marketing field has consistently revealed that collaboration with customers, suppliers, research institutions and competitors is decisive for achieving success. In addition, empirical studies have shown that business relationships are correlated and interconnected with each other. Marketing relationships are a very old phenomenon and this topic is one of the most heavily researched subjects worldwide. Analysing the complexity of network relationships accounts for the fact that B2B marketing now involves networks of relationships in which parties are interactive and actively engaged in commencing and strengthening the relationship [10]. Organizations therefore function in a complex commercial environment with a different number of markets, where decisions are made within a set of different interrelationships, for which the organization is responsible to form positive relationships [20]. The interaction process between parties consists of specific episodes, in which the players have diverse goals in the exchange [28,5]. As a relationship unfolds, the parties involved in the process of exchange or in the exchange of elements thereof go through a process of adaptation, which tends to be the lasting deal that is unique to that relationship [5]. Even cautiously planned arrangements may create undesirable exchange relationships between business units. However, where planning exists, this may reflect a lack of trust and blunt the demands on the relationship. The greater danger perceived by some businessmen is therefore that one side would be performing their side of the deal and therefore losing what is called "flexibility" [25].

\section{Background}

By scrutinizing empirical studies in literature, it is possible to determine those variables that are fruitful predictors of relationship performance. Grayson conducted and presented the results of survey data from more than 685 direct-selling

\footnotetext{
*Corresponding author: anna.abeltina@gmail.com
} 
agents, whereby the relationship between supervisors and supervisees was measured. The study results illustrate the role of conflict management and friendship in the work environment. Studies state that combining friendship and business in the same relationship can be beneficial, but that it can create conflict. The source of this conflict tends to be incompatible relational expectations. This article also addresses role theory and reveals that the theory is based on the premise that effective social interaction depends on a shared understanding of relationship rules - that is, the behaviours that are (in)appropriate for different people in different social situations. According to the findings, the source of conflict between business relationships and friendships is that the expectations of the former encourage an instrumental orientation whereas those of the latter encourage an exclusively intrinsic orientation [15]. In addition, Grayson argues that business relationships encourage an instrumental orientation and friendships encourage an intrinsic orientation, while Halpern expresses the idea that exchange between strangers may be characterized more as transactional exchanges, while between friends it may be seen as more relational $[15,18]$. Fiske and Taylor put forward the ideas of 'cognitive structures' and the 'cognition-behaviour relationship', whereby people might maintain mental models, thereby arguing that, how people behave in a particular situation depends on their definition of the relationship and on the personal goals, which they customize according to the situation [11]. In contrast, the friendship script, illustrated by Halpern, consists of a common interpretation of the voluntary nature of the relationship, of how to sustain the friendship in the future, of how to keep the 'liking' associated with the relationship, and how to achieve equality, mutual self-disclosure, and future interactions [19].

\section{Methodology}

The following research paper adopts a descriptive approach and is mainly focused on an extensive review and analysis of cases, articles and books on the complexity of relationships within the B2B sector. The research includes existing data that can be obtained from the internet, peer-reviewed journals, textbooks, government records and libraries. The intention was to identify some micro and macro factors from which substantial insights could be gained. The predominant research subject in this study was: What strategies do company leaders use to sustain their businesses and establish long lasting relationships? Quantitative research was deemed suitable for this research project. The overall goal of the research was to investigate a specific meaning rather than presenting the findings as absolute truth. The current research tends to be empirical, since it aimed to bring new understanding and meaning to the topic of the complexity of relationships within business and the importance of common ground. The research involved organizing, collating and analysing existing data samples for valid research conclusions. The research process started with the identification and evaluation of gaps in existing knowledge before the adoption of primary research to gather new information. As already highlighted, secondary research involved data assimilation from different sources - internet, libraries, archives, schools and organizational reports.

\section{Results and Discussion}

In a business-to-business setting, customer service and quality stems from products and services, the physical environment, human resources and service encounters. Some research has been conducted that pertains to appraisal of customer satisfaction to embrace both product related and service variables. These streams of research are discussed below. Relationships are about time and behind every relationship there is a history, which makes it what it is for the present and sets the guidelines for the future, no matter whether the relationship is long or short term [12,5]. A relationship, as defined by Bachnik, means a connection, whereby it is perfectly rational that a relationship is a connection to a higherlevel, one beyond the relationship between oneself and another, but rather to a social order. For example, in Japan, relationships are seen not as the lowest level building blocks of society, which must be included into higher levels, but as organizing factors themselves [1]. Therefore, it makes it difficult for foreigners to break into the Japanese system as suppliers [18]. Friendship is bound by a set of alternative relationships that mark off its explicit extents and belongings and is abound within a given culture [22]. Mass marketing has given way to mass customisation, which in turn calls for companies to adapt to customers' needs quickly and to operate without geographic boundaries and to regulate multinational intra-organisational relationships [9]. Similar to many other paradigms, relationship marketing emerged as a new paradigm. Nevertheless, we can find many terms describing relationship marketing, like: "customer relationship management", "database marketing", "customer loyalty" and the most recent, "customer experience", which is the emotional embodiment of a customer to a brand [2]. Not meeting customer needs well and being indifferent to customer wants can cause reductions in sales for companies. Therefore, it becomes imperative for marketers to restructure their strategy and to follow and monitor the action of some customer segments. As a result, relationship marketing emerged [4]. The term customer relationship management (CRM) has been used since 1990s. We can distinguish 4 types of customer relationship management, as illustrated in Figure 1: 


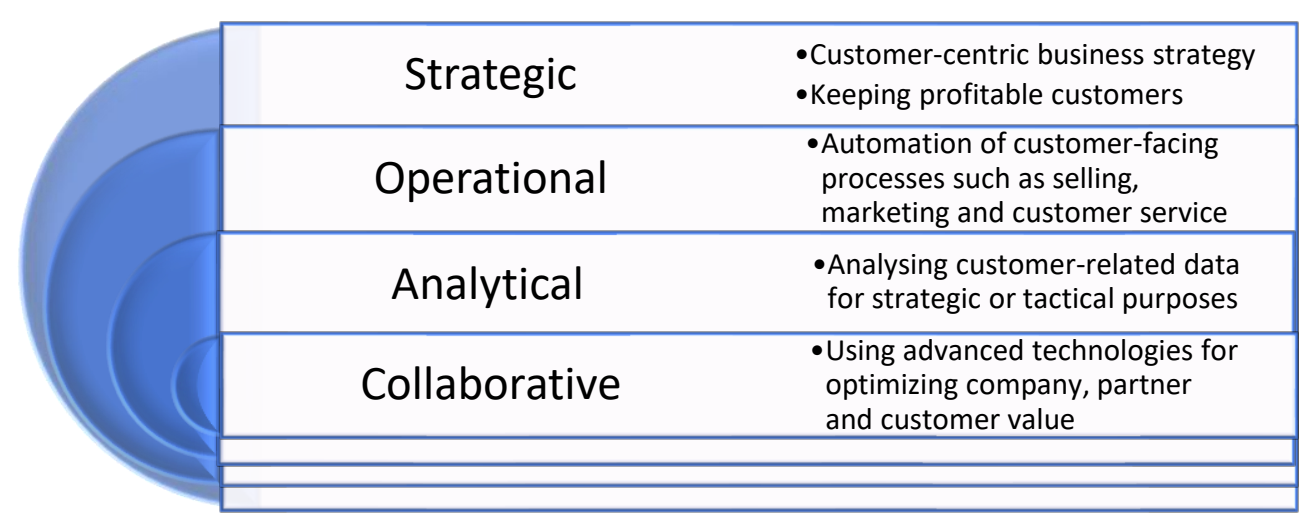

Figure 1. Types of CRM

Source: Authors based on Buttle [6].

Strategic CRM concentrates on building and establishing long lasting relationships with customers. For this purpose, the company orients its processes, technologies and people towards serving customers efficiently and effectively. Whereas, for operational CRM, the company atomizes inside procedures. For processing, interpreting, distributing, using and reporting customer-related data, analytical analyses are conducted. Examples of collaborative CRM are: category management, collaborative forecasting, joint new product development and joint market research [6].

A company has to deal with a set of relationships, that is a network of interactions. Relationships can develop as a result of the consequences of extensive collaboration and/or competition. Where the collaborative part is minor and is compensated by competition, it becomes important to divest the relationship or to work to reinforce it [16]. There is a strong correlation between customer retention and corporate profitability. The right and positive development of customer relationship marketing or customer management can be beneficial not only for companies, but for society as a whole [23]. As the main priority is retaining and sustaining long-term relationships with customers, relationship marketing therefore encompasses three levels:

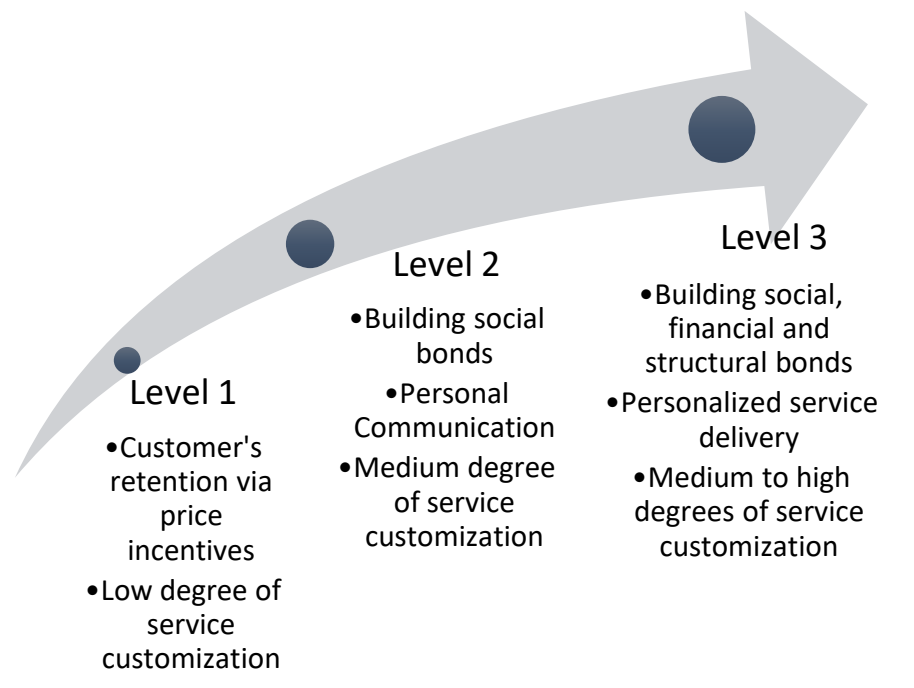

Figure 2. Three levels of relationship marketing

Source: Authors based on Berry and Parasuraman [3].

Marketing relationships should not only be seen as an exchange and interaction of networks. It should be viewed as an on-going relationship that deals with various channels of marketing and relationships. It encompasses the relationships between business marketing, marketing channels, service marketing, database marketing and direct marketing [26].

The following can be concluded on the basis of an analysis of relationship embeddedness and role theory. Montgomery suggests that role theory is a discrete alternative to rational choice theory, which might permit a more realistic demonstration of embeddedness [27]. Granovetter argues that behaviour has become much more autonomous with modernization, but is heavily embedded in social relations in premarket societies [14]. Frenzen and Davis introduced the theory of a broadened concept of utility as the basis for officially typifying embeddedness at the level of the individual purchaser [13]. The source of conflict between business relationships and friendships tends to be an instrumental or exclusively intrinsic orientation. However, commercial relationships may be attached more plainly in instrumental goals than work relationships are [29]. Embeddedness, interpersonal relationships and social bonds are crucial aspects of relationships [21]. Therefore, it is obvious to conclude that conflict is a natural and even inevitable aspect of most ongoing 
close relationships. So, the issue that differentiates successful from unsuccessful relationships is not whether there is conflict but how it is handled [7]. We should also take into account the fact that, adjustment of exchange relationships and dispute settlement by proceedings or the danger of it also has many costs. The gain anticipated from using this form of compulsion often fails to outweigh these costs, which are both monetary and non-monetary [25]. The Industrial Marketing and Purchasing Group (IMP Group) developed interaction approach based on the data collected from the interviews of 878 buyers and sellers from 318 firms in France, Italy, Germany, Sweden and the UK. As the results of the survey reveal, buyer-seller interaction is a dyadic interaction and the interaction at both firm and individual levels is influenced by the atmosphere, power and dependence cooperation, expectations, closeness and the environment [17]. In addition, it is concluded that it is pivotal that companies examine and assess each relationship be it national or international and to make decisions about organisational restructuring based on it [8]. Lewis and Craven examined the significance of 40 criteria in choice of a supplier and 18 criteria that would influence the replacement of an existing supplier. They found dimensions of service quality relating to product, the organization and its personnel to be the most important factors [24]. SMEs have a crucial role upon world economy and play a vital role in generating jobs and income. In this rapidly changing world, as customer needs change swiftly, SMEs are challenged to make unique selling propositions, to improve quality and to add value to products or services to accommodate those needs. For these organizations, it tends to be challenging to manage complex relationships with suppliers, customers and financial stakeholders. The capacity of SMEs to grow is rooted in abundant factors and none of them should be taken too lightly. The survey conducted by the authors related to innovation with the title: "Innovation as a pathway to business growth in SME's in Latvia" highlighted some aspects that could be linked to the present research. The research was analytical and the opinions of 110 SMEs from various manufacturing and service industries in Latvia were captured through an online survey. As the survey results revealed, $95 \%$ of respondents considered innovation to be the most critical internal factor for promoting SME growth. The second most crucial internal factor was human and technological resources. Quality improvement was selected as the most important platform for a company to drive its innovation practices, the percentage distribution was 35\%. This was followed by market competition response, which was selected by 22 respondents. The results of the research show that various internal and external factors affect the development and growth of SMEs. Therefore, it is fundamental for SMEs to respond to customer needs by offering innovative services and products, as well as to draw up a strategy which takes into consideration the needs of all stakeholders and helps find common ground.

\section{Research limitations}

Taking into consideration that present research is exploratory in nature and it cannot be applied to general public, it has some limitations. Secondary information offers comparatively fast and inexpensive answers to many questions and generates some foundations for primary research. Nevertheless, research materials in secondary research are not exclusive to an individual or group. This means that everyone has access to the data and there is little or no information benefit obtained by those who attain the research. Consequently, coherent disadvantage was that, the data was not specifically designed to meet specific needs and were too general.

Even though the internet could afford excellent research materials, the web pages and commercial sites often has a marked bias and much of the information tends to be obsolete and not reliable. As a result, it became inevitable to conduct cross check comparison of the data from one organization with data from another source. It is important to note that this research relied on the outcomes of collective secondary research data and that it had the inherent risk of outdated research materials. In addition, it was hard to determine the authenticity of the data. Invalid data could have affected the research outcomes negatively hence, it was important to take extra care by evaluating the data before making use of it.

\section{Conclusion}

Organizations operating in a global environment are constantly looking to change their operations, whether it be in production or the service sectors, and to respond to worldwide challenges. From the moment a business enterprise is established, it follows a certain business model that bonds technical potential with the realization of economic value. The organization directly or indirectly develops a business model that defines the manner and means by which to create value. The quintessence of it is describing the method and process by which the services and products are developed and then delivered and supplied to customers. Subsequently, customers reimburse suppliers and service providers for the value received and these payments in turn convert into profits for organizations. Consequently, it gives the direction to an organization to scrutinize what customers desire and how those needs are met. One of the challenges companies have to overcome is to establish relationships with suppliers and clients based on trust and fruitful cooperation. It requires organizations to invest more in customer relationship management programs and to utilize all human resource potential for building a strong network of relationships. Those organizations that are capable of responding quickly and proactively to market changes are the ones who reap the benefits. The basic feature of relationships still remains communication because it is the social glue that bonds corporations together. However, communication has evolved over the years and has dramatically advanced due to novel technologies. Analysing the descriptive nature of the research, we can conclude that organizations that manage complex relationship patterns well are the ones who survive fierce competition. Also, relationship management requires common ground, a culture, a language, a set of common values and shared objectives. This article also illustrated the notion of a perfect friendship and concludes that there should be no hidden motives in the 
relationship and selfish and instrumental concerns should be avoided. In addition, conflict is seen as inevitable and natural to all organizations and it does exist. The success of an organization is determined by how well managers handle conflict and manage relationships in the face of those conflicts. Interpersonal relationships can facilitate problem solving and can guarantee social gratification and therefore enhance trust and assurance in a partnership and friendship. Likewise, to sum up the main findings of the research, relationships that are based on friendship are more sensitive to conflict than relationships that begin as a business relationship. Within this context, relationship embeddedness demands huge effort and time, whereby it is extremely hard to turn a business partnership into a friendship. Lastly, the study reveals that combining friendship and business in the same relationship can be advantageous, but that it can create conflict, which is often the result of a mismatch in interpersonal anticipations.

\section{References}

1. J. Bachnik, Time, Space and Person. In J. Hendry, Japanese relationships' in Interpreting Japanese society anthropological approaches. $2^{\text {nd }}$ ed. London: Routledge, 94 (1998)

2. D. Bejou, A. Palmer, The future of relationship marketing. New York: Best Business Books (2006)

3. L. L. Berry, A. Parasuraman, Marketing services: competing through quality. New York: The Free Press, 136-139 (1991)

4. S. Biswas, Relationship marketing: concepts, theories and cases. Delhi: PHI Learning Private Limited, 2-4 (2014)

5. R. Brennan, L. Canning, R. McDowell, Business-to-Business marketing. London: SAGE publications ltd., 73 (2007)

6. F. Buttle, Customer relationship management: concepts and technologies. Oxford: Elsevier, 4 (2009)

7. D. Canary, W. Cupach, S. Messman, Relationship conflict. London: Sage publications (1995)

8. M. T. Cunningham, International Marketing and Purchasing of Industrial Goods Features of a European Research Project. European Journal of Marketing. 14 (5/6), 322-338 (1980)

9. B. Donaldson, T. O’Toole, Strategic market relationships: from strategy to implementation. Chichester: John Wiley \& Sons (2007)

10. C. Fill, Business-to-Business Marketing: Relationships, Systems and Communications. Harlow: Financial Times Prentice Hall (2005)

11. S. T. Fiske, S. E. Taylor, Social cognition. $2^{\text {nd }}$ ed. New York: McGraw-Hill Inc. (1991)

12. D. Ford, P. Berthon, P. Brown, The Business Marketing Course: managing in complex networks. Chichester: John Wiley (2002)

13. J. K. Frenzen, H. L. Davis, Purchasing Behaviour in Embedded Markets. Journal of Consumer Research. 17(June) (1990)

14. M. Granovetter, Economic Action and Social Structure: The Problem of Embeddedness. The American Journal of Sociology. 91(3), 481-510 (1985)

15. K. Grayson, Friendship versus business in marketing relationships. Journal of Marketing. 71(October), 121-139 (2007)

16. E. Gummesson, Total relationship marketing. Oxford: Butterworth-Heinemann (2002)

17. H. Håkansson, International Marketing and Purchasing of Industrial Goods: An Interaction Approach. Chichester,: Wiley (1982)

18. J. Halpern, Elements of a script for friendship in transactions. Journal of conflict resolution. 41(6), December, 835868 (1997)

19. J. J. Halpern, The Effect of Friendship on Personal Business Transactions. The Journal of Conflict Resolution. 38(4), 647-664 (1994)

20. T. Harwood, T. Garry, A. Broderick, Relationship Marketing, Perspectives, Dimensions and Contexts. Berkshire: McGraw-Hill Higher education (2008)

21. D. L. Haytko, Firm-to-Firm and Interpersonal Relationships: Perspectives from Advertising Agency Account Managers. Journal of the Academy of Marketing Science. 32(3), 312-328 (2004)

22. D. Konstan, Friendship in the classical world. Cambridge: Cambridge University Press (1997)

23. P. Kotler, Marketing insights from A to Z: 80 concepts every manager needs to know. Hoboken, NJ: J. Wiley \& Sons (2003) 
24. B. R. Lewis, P. Craven, The Role of Customer Service in Buyer-Seller Relationships: Evidence from The Industrial Gases Market. In: P. W. Turnbull, D. Yorke, P. Naudé. IMP Conference (11th): Interaction, Relationships And Networks: Past - Present - Future. United Kingdom: Manchester (1995)

25. S. Macauley, Non-contractual relations in business: a preliminary study. American sociological review. 28(1), 55-67 (1963)

26. K. Möller, H. Aino, Relationship Marketing Theory: Its Roots and Direction. Journal of Marketing Management. 16(1-3), 29-54 (2000)

27. J. D. Montgomery, Toward a Role-Theoretic Conception of Embeddedness. American Journal of Sociology. 104(1), 95-125 (1998)

28. P. Naudé, C. Holland, Business-to-Business Relationships. In F. Buttle, Relationship Marketing: theory and practice. London: Paul Chapman Publishing Ltd. (1996)

29. L. L. Price, E. J. Arnould, Commercial friendships: Service provider--client relationships in context. Journal of Marketing. 63(4), 38-56 (1999) 